\title{
GRAPHENE OXIDE REINFORCED POLY (VINYL ALCOHOL) NANOCOMPOSITE: FABRICATION AND CHARACTERIZATION FOR THERMAL AND MECHANICAL PROPERTIES INVESTIGATIONS
}

\author{
Sami MAKHARZA ${ }^{1,2^{*}}$, Maryam FAROUN ${ }^{2}$, Mohammad BAWWAB $^{3}$, Ibrahim AFANEH A $^{2,3}$ \\ ${ }^{1}$ College of Pharmacy and Medical Sciences, Hebron University, Hebron, Palestine \\ ${ }^{2}$ Nanotechnology Center, Al-Quds University, Jerusalem, Palestine \\ ${ }^{3}$ Faculty of Engineering, Al-Quds University, Jerusalem, Palestine
}

Received 07 October 2019; accepted 09 April 2020

\begin{abstract}
We reported the fabrication of poly (vinyl alcohol) incorporated with two different sizes of graphene oxide particles. Scanning electron microscopy (SEM) revealed two sizes of graphene oxide, the first size is as prepared GO_300 nm and the second size is $100 \mathrm{~nm}$ after hard sonication. The alteration in thermal and mechanical properties of PVA/ GO (5, $10,15,20 \%$ ) nanocomposite compering with PVA are mainly due to the uniform dispersion of GO particles in the polymer matrix and huge interfacial interaction between PVA and GO sheets. Differential scanning calorimetry shows obvious changes in thermal characteristics of PVA after mixing with GO particles. The composite samples exhibit a significant finding at different concentrations and size distribution of GO.
\end{abstract}

Keywords: graphene oxide, tensile strength, stress strain curve, PVA degradation.

\section{Introduction}

Graphene, a freestanding material consists of a single layer of sp2 bonded carbon atoms in hexagonal like structure (the strongest material ever measured). It has been considered as an extraordinary in-demand materials after its discovery in 2004 (Novoselov et al., 2004, 2005). The excellent properties and inexpensive sources (graphite) have provoked intensive interest in developing high performance graphene oxide based polymer nanocomposite (Ionita et al., 2014; Kim \& Macosko, 2009; B. Y. Lee \& Kim, 2013; Ou et al., 2012; Yu et al., 2014). Figure 1a shows the chemical structure of graphene oxide layer and both single and multiple carbon nanotubes used as carbon nanomaterials in construction applications. Figure $1 \mathrm{~b}$, exhibits the number of publications during recent years, it seems that the interest of graphene oxide increasing rapidly as well as carbon nanotubes. Several studies have demonstrated exciting aspects of graphene oxide particles, including high thermal conductivity and mechanical strength comparable to carbon nanotubes (Mansor et al., 2019; Xue et al., 2019). The presence of oxygen groups decorated graphene will improve the hydrophilicity and the dispersibility in polar solvents. This behavior in dispersibility will provide graphene oxide particles the ability to be incorporated into polymer matrices for thin film fabrication. It leads to increase the percolation threshold (filler loading fraction) for electrical application (Atif et al., 2016; Sengupta et al., 2011).

The functionality of graphene and its derivative GO comparing with CNTs in industrial applications is mainly related to the high surface to volume ratio because of the inaccessibility of CNTs surface to polymer molecules. This makes graphene potentially more acceptable for enhancing the mechanical, thermal and electrical properties of polymer matrices (Xu et al., 2009).

There are several procedures to prepare graphene oxide, the first method was in the 1850's by oxidizing graphite with $\mathrm{KClO}_{3} / \mathrm{HNO}_{3}$ (Brodie, 1859). Since then the experimental conditions like oxidizing agents, temperature, and reaction time were controlled in order to prepare GO with relatively high oxygen to carbon ratio as well as eliminate any reaction traces (contaminations) generate during the oxidation. The reinforcement of graphene oxide in polymer matrices occurs via different methods like solution casting method.

${ }^{*}$ Corresponding author. E-mail: samim@hebron.edu 
Polyvinyl alcohol is considered as one of the most polymers due to good mechanical and thermal properties, impact resistance and optical transparency ( $\mathrm{Du} \&$ Cheng, 2012; Omar et al., 2019). The morphological organization, fine interface control, uniform dispersion, and ease of processing should be considered as a challenging issue in order to optimize the performance of the resulting composites.

The mechanical characteristics of graphene monolayer as $\mathrm{sp}^{2}$ regime are well reported; it shows a break strength of $42 \mathrm{~N} \mathrm{~m}^{-1}$, a Young's modulus of $1.0 \mathrm{TPa}$, and a tensile strength of $130.5 \mathrm{GPa}$ (C. Lee et al., 2008; Smith et al., 2019). Zhang et al. reported that the toughness of graphene sheet is approximately $4.0 \pm 0.6 \mathrm{MPa} \mathrm{m}^{1 / 2}$, confirming the low fracture of pristine graphene (Zhang et al., 2014). Many scientific reports exhibited mechanical properties of GO are notably high, but less than that of pristine graphene sheet, this behavior attributed to the disorder of $\mathrm{sp}^{2}$ pattern as well as different functional groups decorated the surfaces of graphene oxide sheets. GO nanoparticles produced by Hummer's method revealed a Young's modulus of 207.6 $\pm 23.4 \mathrm{GPa}$ (Suk et al., 2010) and 250 $\pm 150 \mathrm{TPa}$ with thermal annealing in hydrogen gas (Gómez-Navarro et al., 2008). These mechanical characteristics of GO added a strong benefit to polymer nanocomposites as fillers. A recent report showed that the incorporation of GO nanoparticles with PVA polymer matrix (20\% GO filler content) will increase the tensile strength of PVA five times compering with pure PVA film (Cheng-An et al., 2017).

Recently, Carbon nanotubes (CNTs) have been extensively studied in nanocomposite materials due to their strong mechanical and thermal properties. However, the metal catalyst generated throughout the fabrication process will trap inside the CNT and produce CNT based metal contaminant. The presence of metals inside CNT will influence the mechanical and thermal behavior of CNT reinforced polymer nanocomposite. Metal-free CNTs are obtained after intensive and time-consuming purification process. Here, graphene oxide particles as an alternative metal-free nanostructure material can be synthesized from graphite via chemical exfoliation reaction.

\section{Experiment}

\subsection{Synthesis of graphene oxide}

GO is prepared via modified Hummers method which was developed in 2010 (Sun et al., 2010). Briefly, in an acidic medium $\left(23 \mathrm{ml}, 95 \% \mathrm{H}_{2} \mathrm{SO}_{4}\right)$, the addition of $3.0 \mathrm{~g}$ of $\mathrm{KMnO}_{4}$ as oxidizing agent $\left(\mathrm{KMnO}_{4}\right)$ to $1.0 \mathrm{~g}$ of graphite powder will produce $1.6 \mathrm{~g}$ dried graphite oxide. The obvious indication for graphite oxide is the color difference between graphite as black to brownish in case of graphite oxide. It is well known that graphite oxide is dispersed well in water as well as any polar organic solvent due to the oxygen groups distributed on graphene basal plane and edges. After oxidation, a horn-tipped ultrasonic Probe sonication with controlled power and time (28.6 W, $120 \mathrm{~min}$ ) was used to reduce the dimensions of graphite oxide layers and achieve GO with excellent dispersibility in solution. Finally, two sizes of GO particles with lateral width 300, $100 \mathrm{~nm}$ were investigated with PVA polymer.

\subsection{Fabrication and characterization of PVA/GO composite film}

The solution casting method was used for fabricating PVA/GO composite materials with different GO percent (5. 10, 15, 20 wt. \%). Briefly, different solutions of GO prepared under optimized conditions of sonication in order to have one phase of GO without aggregation. $10 \mathrm{wt}$. \% of PVA solution prepared under continuous stirring for $12 \mathrm{~h}$. Afterwards, the GO solution was mixed and dispersed in polymer solution by vigorously stirring for $2 \mathrm{~h}$, followed by Ultrasonication for $10 \mathrm{~min}$. the solution then placed on a glass plate for solvent evaporation. The composite was peeled off, washed several times, and kept under vacuum for drying. a)

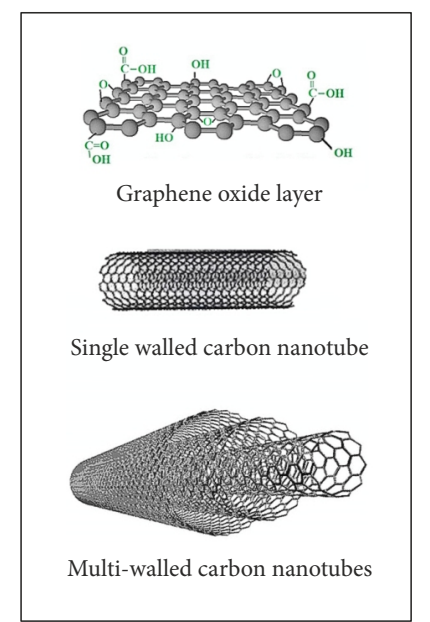

b)

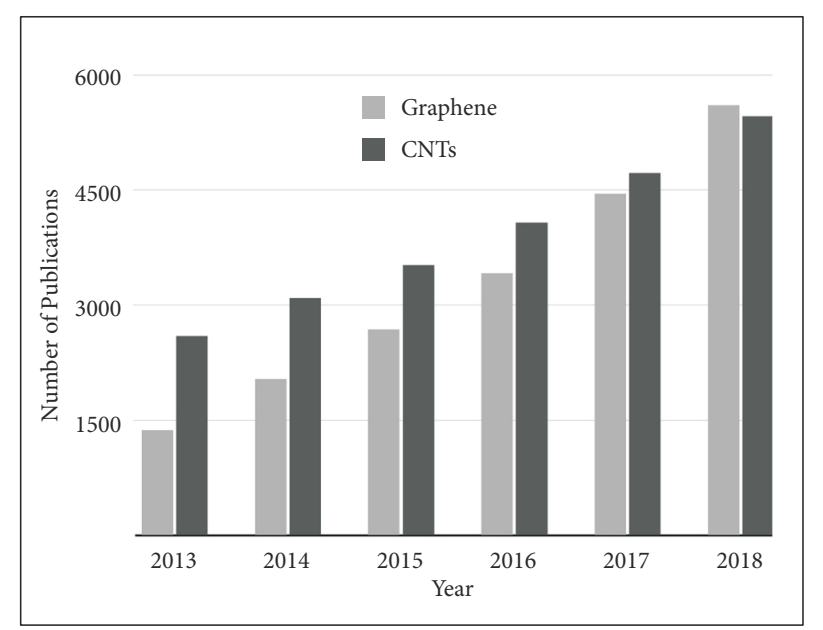

Figure 1. a) - The chemical structure of graphene oxide, single walled CNT and multi-walled CNTs; b) - Number of publications from 2013 to 2018, the data deduced from sciencedirect.com in Jan 2019. (The words used in research filed are polymer, graphene, CNTs, composite, thermal and mechanical applications) 
Scanning electron microscope (SEM) was used to study the structural morphology of the samples as well as estimating the size distribution of prepared particles. Differential scanning calorimetry (DSC) is utilized to understand the thermal properties of GO embedded PVA at different heating and cooling programs. The mechanical tests were performed using an universal mechanical test machine, the dimensions of tested samples was eight centimeters in length and $3.5 \mathrm{~cm}$ in width, the thickness of samples was maintained at $0.15 \mathrm{~mm}$.

\section{Results and discussion}

As shown in panel a, the scanning electron microscope revealed the size of GO particles is approximately $300 \mathrm{~nm}$ before doing ultra-sonication (approximately 250 particle were randomly selected on SEM images for measuring the average size of graphene oxide sheets). After 30 minutes of sonication, the size distribution of GO particles reduced to approximately $100 \mathrm{~nm}$ as shown in Figure 2b. SEM images were obtained using a FEI, NOVA NanoSEM200 with an acceleration voltage of $15 \mathrm{kV}$. The samples for SEM study were deposited on silicon substrate and placed in an oven for $60 \mathrm{~min}$ for solvent evaporation.

The thermal history of PVA/GO composite samples was performed in a PerkinElmer Jade DSC at a heating rate of $10{ }^{\circ} \mathrm{C} / \mathrm{min}$ from $35{ }^{\circ} \mathrm{C}$ up to $520{ }^{\circ} \mathrm{C}$ in a nitro-

a)

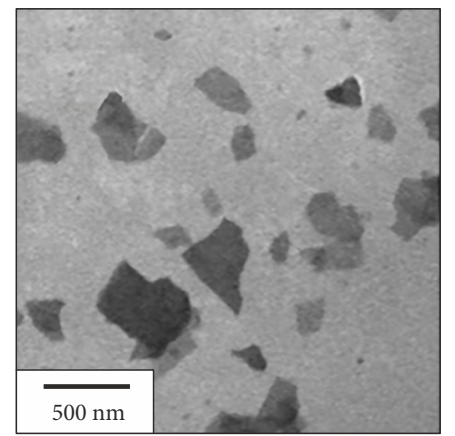

gen atmosphere which allowing the PVA to thermally decompose completely. Thermal analysis was elucidated for the composite samples that had two sizes of GO particles measured after fabrication. The samples were dried at room temperature during two days and after one week of fabrication they were thermally and mechanically characterized.

As shown in Figure 3a, the first transition temperature of PVA occurs at about $105^{\circ} \mathrm{C}$ which represents the glass transition temperature. In the range of approximately $210^{\circ} \mathrm{C}$ to $240^{\circ} \mathrm{C}$ is the melting transformation. Additional peaks are observed at $285^{\circ} \mathrm{C}$ and $333{ }^{\circ} \mathrm{C}$, and these are attributed to the degradation process of the PVA constituents. At 5 and $10 \%$ of GO particles the degradation peak shifted to higher temperature and reach $355^{\circ} \mathrm{C}$, this behavior is due to the crosslinking of graphene oxide flaks incorporated with PVA molecules. At higher concentration of GO $(15,20 \%)$, the degradation temperature of PVA shifted drastically to high temperature above $320^{\circ} \mathrm{C}$. This transformation exhibits the crosslinking is concentration dependent. The interesting thing is the clear change of melting point region, this behavior might be due to the high percent of crosslinking with GO which makes the degradation possible in that region. There is no significant change in the thermal behavior of composite at two sizes of GO particles. The data obtained by using DSC Perkin Elmer 4000.

b)

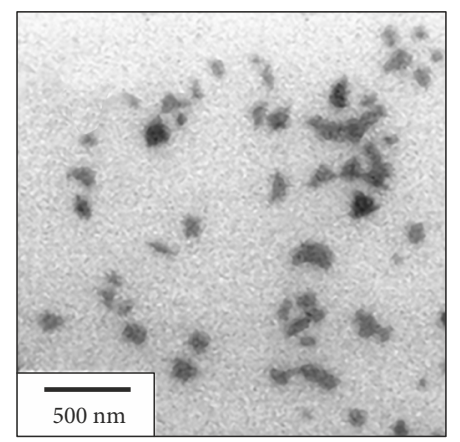

Figure 2. The SEM images of (a) $300 \mathrm{~nm}$ and (b) $100 \mathrm{~nm}$ of graphene oxide on silicon substrate
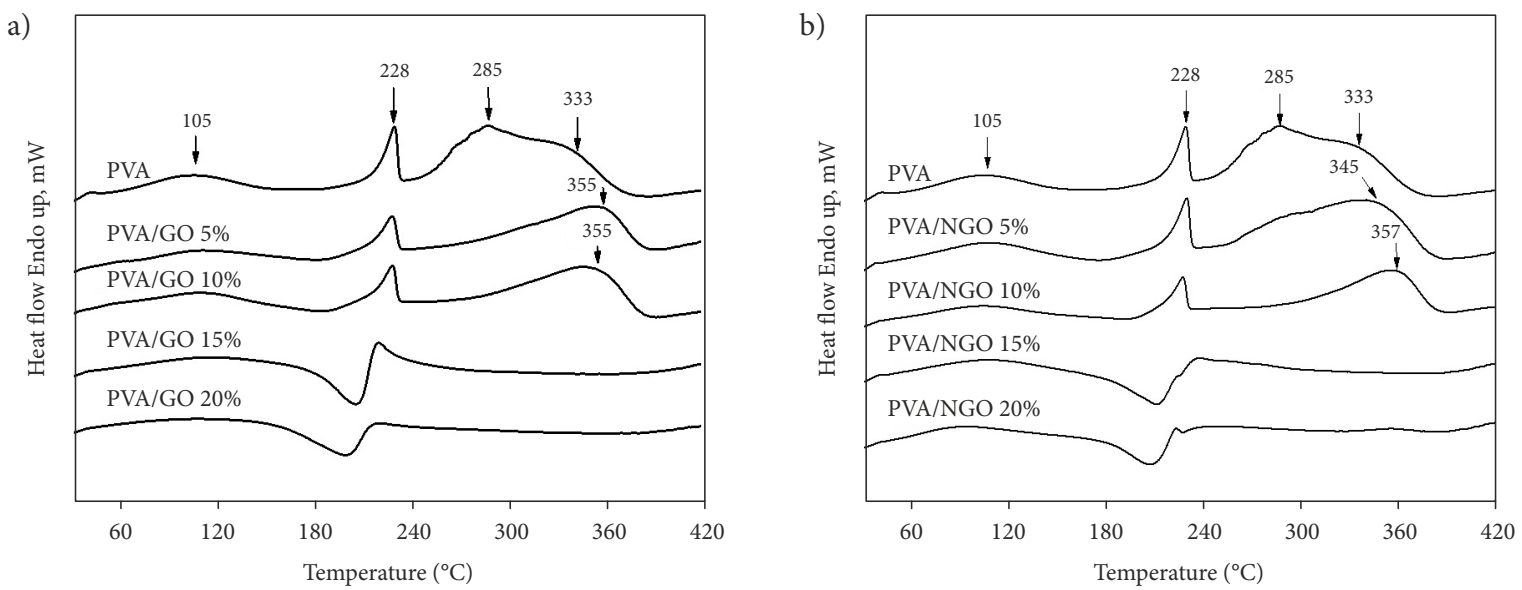

Figure 3. DSC of PVA/GO composite: a) - PVA and PVA/GO composite at size distribution of GO 300 nm; b) - PVA and PVA/GO composite at size distribution of GO $100 \mathrm{~nm}$ 

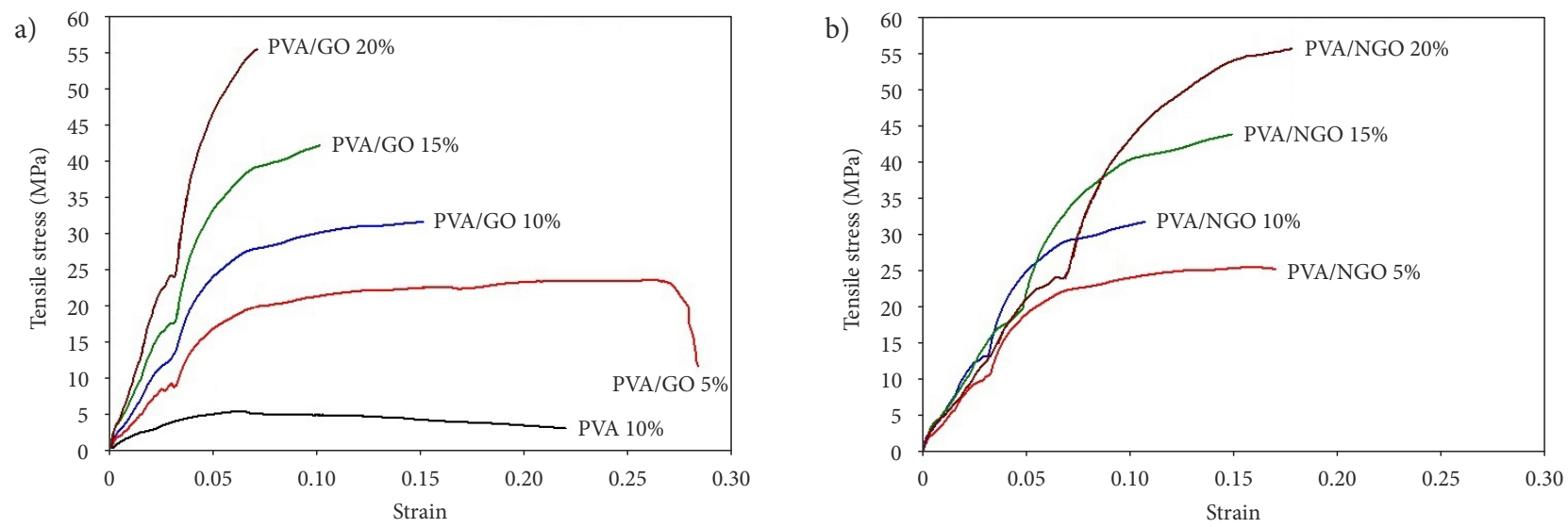

Figure 4. Tensile stress strain curves: a) - Free PVA, PVA/GO 5\%, PVA/GO 10\%, PVA/GO 15\% and PVA/GO 20\%; b) - PVA/NGO 5\%, PVA/NGO 10\%, PVA/NGO 15\% and PVA/NGO 20\%

The thickness of all samples for mechanical properties investigation was maintained at $0.15 \mathrm{~mm}$. Free PVA film exhibits 5.5 MPa of tensile strength, by incorporating graphene oxide particles in PVA polymer the tensile strength increased up to $23.6 \mathrm{MPa}$ with noticeable elongation at break. By increasing the percent of GO up to $20 \%$ in polymer matrix the tensile strength increased to approximately $57 \mathrm{MPa}$ with 0.07 strain at break as shown in Figure 4a. In panel $\mathrm{b}$, the composite films at 5, 10, 15 and $20 \%$ of NGO $(100 \mathrm{~nm})$ revealed small variation ultimate tensile strength and strains comparing with GO $(300 \mathrm{~nm})$. These results indicated that the GO particles cross-linked in polymer chains. The measurements attained by using Universal Mechanical Test Machine, Sinowon Testing Mchines ST series.

\section{Conclusions}

Two sizes of GO particles ( $300 \mathrm{~nm}$ and $100 \mathrm{~nm}$ ) can be reinforced into PVA polymer via simple casting at different concentrations. The incorporation of GO nanoparticles in polymer matrix improves the thermal characteristics of free PVA by using differential scanning calorimerty. The PVA/GO composites at 5, 10, 15 and $20 \%$ of GO particles are strong and ductile. The tensile strength and ductility for composites containing GO 300nm is higher than those in free PVA. Moreover the mechanical and thermal properties of PVA are enhanced after reinforcing NGO $100 \mathrm{~nm}$ in polymer film.

\section{References}

Atif, R., Shyha, I., \& Inam, F. (2016). Mechanical, thermal, and electrical properties of graphene-epoxy nanocomposites-A review. Polymers, 8(8), 281.

https://doi.org/10.3390/polym8080281

Brodie, B. C. (1859). On the Atomic Weight of Graphite. Philosophical Transactions of the Royal Society of London, 149(12), 249-259. https://doi.org/10.1098/rstl.1859.0013

Cheng-An, T., Hao, Z., Fang, W., Hui, Z., Xiaorong, Z., \& Jianfang, W. (2017). Mechanical properties of graphene oxide/polyvinyl alcohol composite film. Polymers and Polymer Composites, 25(1), 11-16. https://doi.org/10.1177/096739111702500102

Du, J., \& Cheng, H.-M. (2012). The Fabrication, properties, and uses of graphene/polymer composites. Macromolecular Chemistry and Physics, 213(10-11), 1060-1077. https://doi.org/10.1002/macp.201200029

Gómez-Navarro, C., Burghard, M., \& Kern, K. (2008). Elastic properties of chemically derived single graphene sheets. Nano Letters, 8(7), 2045-2049. https://doi.org/10.1021/nl801384y

Ionita, M., Pandele, A. M., Crica, L., \& Pilan, L. (2014). Improving the thermal and mechanical properties of polysulfone by incorporation of graphene oxide. Composites Part B: Engineering, 59, 133-139.

https://doi.org/10.1016/j.compositesb.2013.11.018

Kim, H., \& Macosko, C. W. (2009). Processing-property relationships of polycarbonate/graphene composites. Polymer, 50(15), 3797-3809. https://doi.org/10.1016/j.polymer.2009.05.038

Lee, B. Y., \& Kim, Y. C. (2013). Effect of graphene oxide (GO) dispersion on basic properties of polycarbonate/GO composites. International Journal of Digital Content Technology and Its Applications, 7(11), 287-297.

https://doi.org/10.4156/jdcta.vol7.issue11.36

Lee, C., Wei, X., Kysar, J. W., \& Hone, J. (2008). Measurement of the elastic properties and intrinsic strength of monolayer graphene. Science, 321(5887), 385-388. https://doi.org/10.1126/science.1157996

Mansor, M. R., Fadzullah, S. H. S. M., Masripan, N. A. B., Omar, G., \& Akop, M. Z. (2019). Comparison between functionalized graphene and carbon nanotubes. In Functionalized Graphene Nanocomposites and their Derivatives (pp. 177-204). Elsevier. https://doi.org/10.1016/B978-0-12-814548-7.00009-X

Novoselov, K. S., Geim, A. K., Morozov, S. V., Jiang, D., Zhang, Y., Dubonos, S. V., Grigorieva, V. I., \& Firsov, A. A. (2004). Electric field effect in atomically thin carbon films. Science, 306(5696), 666-669. https://doi.org/10.1126/science.1102896

Novoselov, K. S., Jiang, D., Schedin, F., Booth, T. J., Khotkevich, V. V., Morozov, S. V., \& Geim, A. K. (2005). Two-dimensional atomic crystals. Proceedings of the National Academy of Sciences of the United States of America, 102(30), 1045110453. https://doi.org/10.1073/pnas.0502848102

Omar, G., Salim, M. A., Mizah, B. R., Kamarolzaman, A. A., \& Nadlene, R. (2019). Electronic applications of functionalized graphene nanocomposites. In Functionalized Graphene Nanocomposites and their Derivatives (pp. 245-263). Elsevier. https://doi.org/10.1016/B978-0-12-814548-7.00012-X 
Ou, B., Zhou, Z., Liu, Q., Liao, B., Yi, S., Ou, Y., Zhang, X., \& Li, D. (2012). Covalent functionalization of graphene with poly(methyl methacrylate) by atom transfer radical polymerization at room temperature. Polymer Chemistry, 3(10), 2768. https://doi.org/10.1039/c2py20438j

Sengupta, R., Bhattacharya, M., Bandyopadhyay, S., \& Bhowmick, A. K. (2011). A review on the mechanical and electrical properties of graphite and modified graphite reinforced polymer composites. Progress in Polymer Science, 36(5), 638-670. https://doi.org/10.1016/j.progpolymsci.2010.11.003

Smith, A. T., LaChance, A. M., Zeng, S., Liu, B., \& Sun, L. (2019). Synthesis, properties, and applications of graphene oxide/reduced graphene oxide and their nanocomposites. Nano Materials Science, 1(1), 31-47.

https://doi.org/10.1016/j.nanoms.2019.02.004

Suk, J. W., Piner, R. D., An, J., \& Ruoff, R. S. (2010). Mechanical properties of monolayer graphene oxide. ACS Nano, 4(11), 6557-6564. https://doi.org/10.1021/nn101781v

Sun, X., Luo, D., Liu, J., \& Evans, D. G. (2010). Monodisperse chemically modified graphene obtained by density gradient ultracentrifugal rate separation. ACS Nano, 4(6), 3381-3389. https://doi.org/10.1021/nn1000386

Xu, Y., Hong, W., Bai, H., Li, C., \& Shi, G. (2009). Strong and ductile poly(vinyl alcohol)/graphene oxide composite films with a layered structure. Carbon, 47(15), 3538-3543. https://doi.org/10.1016/j.carbon.2009.08.022

Xue, G., Zhang, B., Sun, M., Zhang, X., Li, J., Wang, L., \& Song, C. (2019). Morphology, thermal and mechanical properties of epoxy adhesives containing well-dispersed graphene oxide. International Journal of Adhesion and Adhesives, 88, 11-18. https://doi.org/10.1016/j.ijadhadh.2018.10.011

Yu, Y.-H., Lin, Y.-Y., Lin, C.-H., Chan, C.-C., \& Huang, Y.-C. (2014). High-performance polystyrene/graphene-based nanocomposites with excellent anti-corrosion properties. Polymer Chemistry, 5(2), 535. https://doi.org/10.1039/c3py00825h

Zhang, P., Ma, L., Fan, F., Zeng, Z., Peng, C., Loya, P. E., Liu, Z., Gong., Y., Zhang, J., Zhang, X., Ajayan., P. N., \& Lou, J. (2014). Fracture toughness of graphene. Nature Communications, 5, 1-7. https://doi.org/10.1038/ncomms4782 